\title{
Falsch positive Befunde im Toxocara-ELISA hervorgerufen durch Fasciola-Antikörper
}

\section{False-positive Results in the Toxocara-E/S-ELISA produced by Fasciola-Antibodies}

\author{
Magretha Saathoff, G. Pereira' \\ Institut für Medizinische Parasitologie der Universität Bonn (Direktor: Prof. Dr. med. H. M. Seitz) \\ 'z. Z. Institut für Med. Parasitologie
}

\begin{abstract}
Zusammenfassung:
Mehrere Serumproben von Patienten mit Fasciola hepatica-Befall reagierten im Toxocara-ELISA mit E/S-Antigen (käufliches Kit) positiv. Im indirekten Immunofluoreszenztest mit Kryostatschnitten von embryonierten Toxocara-Eiern als Antigen zeigte sich lediglich eine starke Schalen-Reaktion. Die Larvenanschnitte gaben in allen Fällen einen negativen Befund.
\end{abstract}

Schlüsselwörter:

Toxocara-E/S-ELISA - Fasciola-Antikörper - Toxocara-Serodiagnostik - IIFT mit embryoniertem Ei-Antigen

\begin{abstract}
Summary:
Several sera from patients with confirmed Fasciola hepatica infection were found positive when tested against Toxocara-E/S-antigen in the ELISA (commercial test kits). When those sera were screened against embryonated Toxocara-eggs as antigen (cryosections) using an IFAT they produced only a strong fluorescence on the Toxocara egg shell. None of the sera was reactive with the Toxocara-larvae in the IFAT.
\end{abstract}

Keywords:

Toxocara-E/S-ELISA - Fasciola antibodies - Serodiagnosis of human toxocariasis - IFAT with embryonated eggs as antigen

In den letzten Jahren wurden uns mehrere Serumproben, die im Toxocara-ELISA mit Exkretions/Sekretions(E/ S)-Antigen (kommerzielle Kits) positiv reagiert hatten, zur Untersuchung im indirekten Immunofluoreszenztest (IIFT) zugeschickt.

Bei der Untersuchung dieser Seren im IIFT mit Kryostatschnitten von embryonierten Toxocara canis-Eiern als Antigen fanden wir in keinem Fall homologe Antigen-Antikörper-Reaktionen. Teilweise ergaben sich negative Befunde (Abb. 1).

Vier Serumproben brachten eine intensive Fluoreszenz der Eihülle bei negativer Larven-Reaktion jeweils ab Serumverdünnung $1: 10$ (Abb. 2 ).

Nach unseren Erfahrungen ist das in Abbildung 2 gezeigte Fluoreszenzmuster für Toxocara-Antikörper absolut atypisch. Serumproben von Personen mit dem für Toxocara-Infektionen typischen klinischen Bild geben immer eine intensive Larven-Reaktion. Die Eischale reagiert dagegen nur in den niederen Serumverdünnungen schwach positiv (Abb. 3).

Die in Abbildung 2 gezeigte Schalenfluoreszenz haben wir bisher ausschließlich mit Serumproben von Patienten mit Fasciola-Infektion hervorrufen können. Bei Paralleltitration lag der Schalenfluoreszenztiter jeweils auf gleicher Höhe wie der mit Fasciola-Antigen erzielte AntikörDertiter (je nach Serum 1:80 bis $1: 320$ ). Da Toxocara E/SAntigen von geschlüpften Larven gewonnen wird, ist die positive Reaktion von Fasciola-Antikörpern mit E/S-Anti-

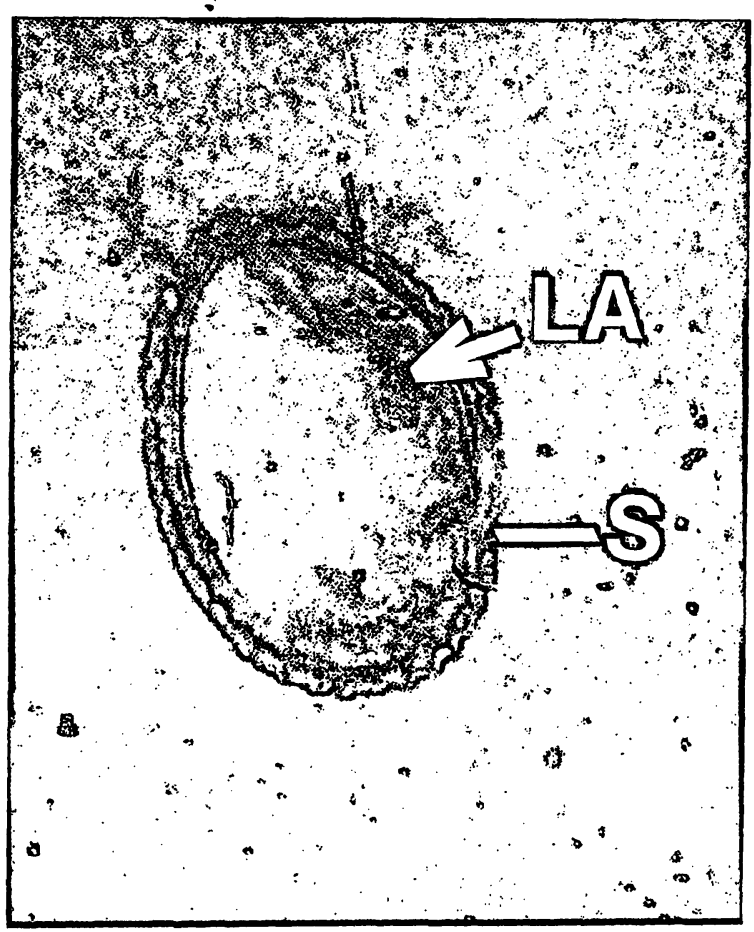

Abb. 1: Negativer Befund im Toxocara-IIFT; als Antigen Kryostatschnitte von embryonierten Toxocara canis-Eiern (Vergr. $\times$ 800). $L A=$ Larvenanschnitt, $S=$ Schale. 


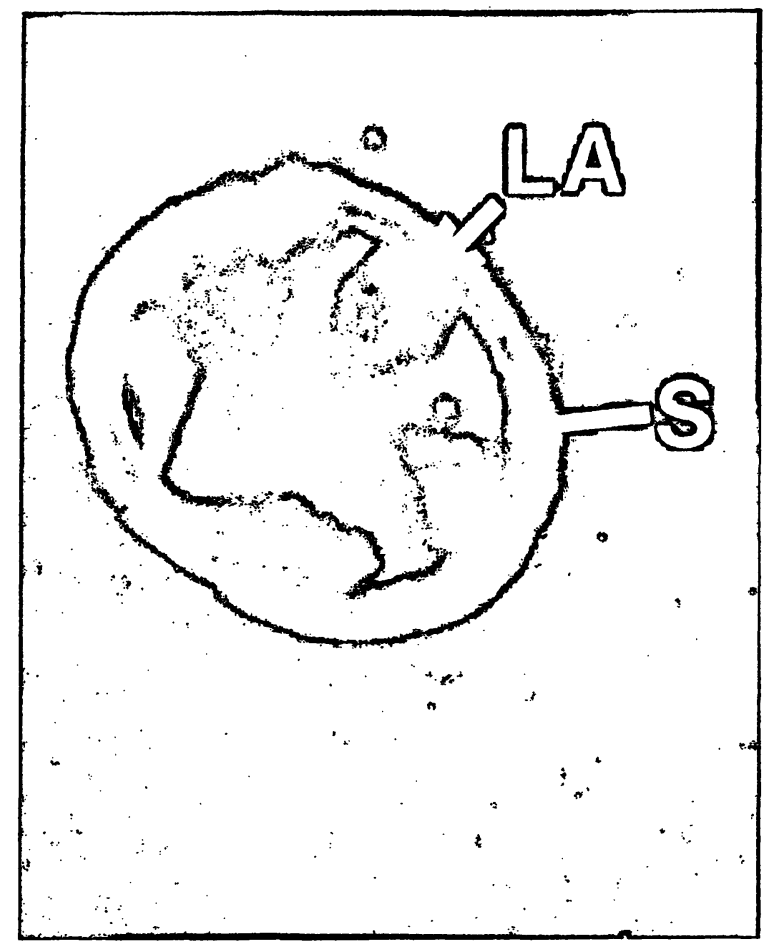

Abb. 2: Schalenfluoreszenzreaktion nach Einwirkung von Fasciola-Antikörpern im IIFT auf Kryostatschnitte von embryonierten Toxocara canis-Eiern (Serumverdünnung 1:80, Antikörpertiter des Serums mit Fasciola-Antigen 1:80) (Vergr. $\times$ 800). LA = Larvenanschnitt, $S=$ Schale.

gen nicht leicht zu erklären; möglicherweise aber durch sauberes Arbeiten bei der Antigen-Gewinnung zu vermeiden. Ist diese Möglichkeit nicht gegeben, müssen positive Befunde im Toxocara-E/S-ELISA also auch auf Kreuzreaktionen mit Fasciola-Antikörpern hin überprüft werden. Wie wir gesehen haben, reichen Stuhluntersuchungen auf Fasciola-Eier nicht aus, um einen Fasciola-Befall sicher auszuschließen. Eier werden je nach Zeitpunkt der Untersuchung nur spärlich oder gar nicht ausgeschieden. Darauf wird auch in der Literatur hingewieșen.

Andererseits gibt es auch Fasciola-Patienten, die genügend Eier ausscheiden, deren Serum im IIFT mit FasciolaAntigen aber nur spärlich oder gar keine Antikörper aụfweist. Bisher haben wir noch nicht untersucht, ob diese Serumproben auch die in Abbildung 2 gezeigte ToxocaraSchalenfluoreszenz hervorrufen.

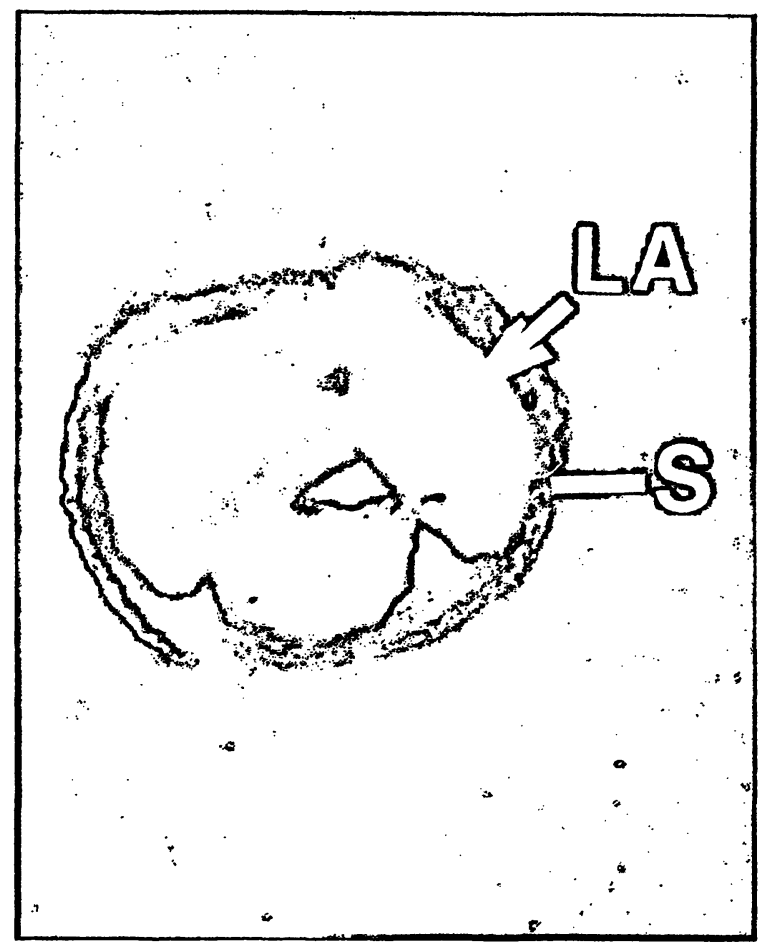

Abb. 3: Kryostatschnitte von embryonierten Toxocara canisEiern nach Ėinwirkung von homologen Antikörpern im IIFT (Vergr. $\times 800) . L A=$ Larvenanschnitt, $S=$ Schale.

Anschrift der Verfasser:

Dr. Magretha Saathoff Institut für Med. Parasitologie der Universität Bonn

Sigmund-Freud-Straße 25 5300 Bonn 1

\section{Dr. G. Pereira}

Facultade de Medicina DCBS

Universidad de Paraiba Campina Grande

Brasilien 